\title{
Le sorgho
}

\author{
Jacques Chantereau, Jean-François Cruz, Alain Ratnadass et al. \\ Presses Agronomiques de Gembloux, Quae, CTA, \\ Gembloux, 2013
}

La collection 'Agricultures tropicales en poche' a été créée par un consortium comprenant le CTA de Wageningen (Pays-Bas), les Presses Agronomiques de Gembloux (Belgique) et les éditions Quae (France). Elle comprend 3 séries d'ouvrages pratiques consacrés aux productions animales et végétales et à des questions transversales en agriculture tropicale. Ces guides pratiques, donc pas forcément scientifiques, sont destinés avant tout à des producteurs, techniciens, et à des vulgarisateurs/conseillers agricoles. Ils se révèlent être également d'utiles sources de références pour les chercheurs, les cadres des services techniques, les étudiants de l'enseignement technique (et académique) supérieur et les agents des programmes de développement rural.

Le présent ouvrage de la série végétale traite d'une céréale d'origine africaine d'importance confirmée. En effet, le sorgho (qui est d'ailleurs une des seules espèces agricoles importantes à avoir ses origines dans le continent africain) occupe la $5^{\circ}$ position des céréales vivrières au monde en termes de quantités produites annuellement, en venant après le maïs, le riz, le blé et l'orge. Mais ce qu'il y a, c'est que le sorgho est, dans bien des régions intertropicales et surtout en Afrique, une culture primordiale dans les agricultures familiales des zones semi-arides et subhumides où il joue un rôle de culture alimentaire de subsistance. Sa rusticité, ses exigences modérées en eau et la résistance à la sécheresse des variétés locales utilisées sont des qualités essentielles pour les agriculteurs dotés de moyens techniques et financiers modestes.

Le sorgho cultivé présente une très grande diversité de formes qui se déclinent en cinq races décrites et présentées dans cet ouvrage (chapitre 2). Cette variabilité génétique et phénotypique se traduit par une grande variabilité d'aspects et d'utilisations. La taille des plantes de sorgho est très variable, allant de 0,5 à 5-6 m pour certaines variétés ; la forme et la compacité des panicules sont elles-mêmes très diversifiées ; la taille et le poids de rooo grains sont aussi très variables, allant de 6 à $85 \mathrm{~g}$ pour Iooo grains (chapitre 4). Une des particularités du sorgho est l'importance du photopériodisme qui s'exprime chez un nombre de variétés tropicales. Le chapitre 5 en rend compte et aide à comprendre les différences importantes qui existent entre les variétés qui sont photopériodiques et celles que ne le sont pas. Un large champ de méthodologie de sélection s'applique au sorgho qui permet aussi bien l'amélioration participative de variétés pour les petits producteurs 
que la création de lignées ou hybrides destinés à une agriculture à l'intensification raisonnée (chapitres 7 et 8). La grande plasticité adaptative du sorgho explique qu'il soit à la base de nombreux systèmes de culture. Le chapitre 9 en présente un certain nombre, soit en régime pluvial, soit en régime de contre-saison irrigué ou non-irrigué. Il s'agit de tirer profit des aptitudes de rusticité et de préservation des ressources en eau du sorgho pour une agriculture plus durable et productive. L'intérêt agro-écologique du sorgho est plus spécifiquement traité dans cet ouvrage au travers de la gestion intégrée des ravageurs (chapitre 6) ou de son utilisation en rotation ou en culture associée (chapitre 9). Le rôle de la culture du sorgho est également intéressant pour fournir différents types de service agro-écologiques et environnementaux : amélioration et conservation des sols, limitation et remédiation des pesticides, détoxification des sols pollués (chapitre Io).

Les utilisations du sorgho sont aussi très diverses. Le sorgho est d'abord une culture vivrière de base, importante pour les zones arides et subarides. Ses utilisations pour l'alimentation humaine sont diverses (farines, semoules, bouillies... mais aussi 'bières' et autres boissons (non-)alcoolisées). En effet, le sorgho est la base de boissons fermentées très appréciées, comme le dolo ou tô, dans certains pays tropicaux. Des utilisations alimentaires alternatives se diversifient (chapitre 13) : utilisation en boulangerie, produits roulés, farines et boissons nouvelles, etc. Considéré comme une céréale sans gluten, le sorgho présente aussi des avantages nutritionnels pour les personnes intolérantes à ces protéines. Ce dernier avantage, en fera probablement une denrée avec un marché potentiel au nord encore inexploité aujourd'hui. L'utilisation du sorgho pour l'alimentation animale est importante sous deux formes principales : les sorghos fourrages dont tiges et feuilles sont utilisées, en vert ou ensilées, pour l'alimentation des herbivores en régions tropicales et tempérées ; le sorgho grain qui constitue aussi un élément de l'alimentation d'autres animaux domestiques en élevage intensif, notamment des porcs et des volailles, dans certains pays industrialisés, principalement. Enfin, le sorgho offre des potentialités intéressantes d'utilisations traditionnelles et récemment développées et aussi diverses que l'agro-énergie, le sucre (variétés de sorghos sucrés ou sucriers), la biomasse, etc. (chapitre I3). Les aspects liés à la (post-)récolte sont traités pour leurs aspects techniques et en termes de protection contre les ravageurs et autres maladies.

L'ouvrage est bien présenté. Des dessins au trait illustrent pas mal de détails botaniques et autres repris dans le texte. Des photos en couleur illustrent des réalités du champ. Le tout est écrit dans un langage bien abordable, même pour des personnes peu formées en la matière. Un lexique à la fin du livre reprend les principaux termes techniques. La liste des références est assez courte. Une liste de liens internet renvoie à des adresses utiles d'organisations travaillant avec le sorgho. Donc, en tout point, ce travail nous paraît bien présenté et bien documenté et écrit par des spécialistes francophones. Il eut été bien si les auteurs avaient invité d'autres spécialistes d'autres pays et organisations à contribuer à cet ouvrage. Aussi, et vu le mandat du CTA (qui dessert aussi les pays anglo- et lusophones, il eut été bien de prévoir une version anglaise et portugaise, voire même une version électronique, et pourquoi pas une application mobile. Vu aussi la vitesse à laquelle 
se développe le monde, mais aussi la recherche scientifique - aussi sur le sorgho - il serait bien que le CTA se concerte, avec ces partenaires, comment rendre ce genre de publication plus interactive, et aussi de trouver des moyens à ce que le contenu puisse rester à jour. A notre avis, ce dernier point doit impérativement passer par un site web où seront intégrés et présentés les derniers développements scientifiques en la matière, tout en se basant sur le format initial du livre. Ceci nécessite naturellement le développement d'une toute nouvelle approche et attitude des éditeurs envers ce genre de publications. A suivre !

Patrick Van Damme

Laboratoire de l'Agronomie Tropicale et Subtropicale et d'Ethnobotanique, Université de Gand 